\title{
A Prospective Double Blind Study to Evaluate and Compare the Efficacy and Safety of Oral Gabapentin and Oral Clonidine in Reducing Post-Operative Pain and Morphine Consumption in Patients Undergoing Elective Gastrectomy
}

\author{
Israr-ul- Haq1*, Bashir $\mathrm{S}^{2}$, Ahmad Khan ${ }^{2}$, Ali $\mathrm{S}^{2}$, Sunain Khan $\mathrm{A}^{2}$ \\ and Habib $\mathbf{M}^{3}$ \\ ${ }^{1}$ Consultant, Department of Anesthesiology, Govt. Medical College, Srinagar India \\ ${ }^{2}$ Sr. Resident, Shari Kashmir Institute of Medical Science Srinagar India
}

\section{Research Article \\ Volume 3 Issue 3}

Received Date: October 13, 2018

Published Date: November 14, 2018

${ }^{3}$ Post Graduate student, Department of Anesthesiology, Govt. Medical College, Srinagar India

*Corresponding author: Israr-ul- Haq Lone, Consultant, Department of Anesthesiology, Govt. Medical College, Srinagar India, Tel: +91-9622729081; Email: Israrlone@gmail.com

\section{Abstract}

Background: Preoperative medication has a vital role in anesthesia. Gabapentin and Clonidine are compounds, which have been alleged to possess anxiolytic, analgesic, and anticonvulsant properties. The present study evaluated the clinical efficacy of oral premedication with Gabapentin and Clonidine in reducing the postoperative pain and opioid consumption in patients undergoing Gastrectomy.

Methodology: Prospective, randomized, double blind, placebo controlled study was conducted on ninety patients of American Society of Anesthesiologists Grade I and II of age group 45-65 years, allocated to one of the three groups of thirty patients each. Group I received Tab Gabapentin 600mg mg, Group II received Clonidine $100 \mu \mathrm{g}$ and Group III received placebo at 10:00 pm at 10:00 pm the night before and $1 \mathrm{~h}$ before the surgery. A uniform anaesthetic technique was used in all groups. Parameters including sedation scores, post operative pain, opioid consumption and various side effects were assessed.

Results: Demographic variables were comparable. The VAS pain scores at measured times were significantly lower in the gabapentin $(4.43 \pm 0.504,3.53 \pm 0.507,2.53 \pm 0.506,1.33 \pm 0.479,0.55 \pm 0.507)$ group as compared to clonidine ( $5.03 \pm 0.183$, $4.93 \pm 0.450,3.60 \pm 0.724,1.80 \pm 0.847,0.93 \pm 0.450)$ and placebo group $(5.70 \pm 0.651,4.63 \pm 0.490,4.43 \pm 0.504,3.10 \pm 0.712$, $1.77 \pm 0.679)$. The post-operative opioid consumption in Gabapentin group $(15.57 \pm 1.01 \mathrm{mg})$ was significantly less than Clonidine $(19.7 \pm 1.64 \mathrm{mg}, \mathrm{P}<0.05)$ and placebo groups $(25.37 \pm 0.99 \mathrm{mg}) \mathrm{P}<0.001$. There was no significant difference 


\section{Anaesthesia \& Critical Care Medicine Journal}

between the groups regarding the postoperative complications. Number of patients required $>$ one dose of rescue analgesic were highest in placebo (30) group as compared to group I (3) and group II (9).

Conclusion: Our study concluded that administration of $1200 \mathrm{mg}$ of gabapentin or $200 \mu \mathrm{g}$ clonidine preoperatively significantly reduces VAS score and opioid consumption when compared to placebo in patients undergoing Gastrectomy. Also Gabapentin was more effective than clonidine in reducing postoperative pain and morphine use for analgesia.

Keywords: Gabapentine; Clonidine; Postoperative VAS; Gastrectomy; Analgesia

\section{Introduction}

Postoperative pain management is a matter of concern for every anaesthesiologist. Effective pain management is now an integral part of modern surgical practice. Despite recognition of the importance of effective pain control, up to $70 \%$ of patients still complain of moderate to severe pain postoperatively [1]. Uncontrolled perioperative pain may potentiate some of these perioperative pathophysiologies and increase patient morbidity and mortality. Painful surgical incisions involving the abdomen result in a reflex-mediated increase in tone of the abdominal muscles during expiration and in a decrease in diaphragmatic function. The result is reduced pulmonary compliance, muscle splitting, and inability to breathe deeply or cough forcefully [2]. Preventing the establishment of altered central processing by analgesic treatment may result in short-term (e.g., reduction in postoperative pain and accelerated recovery) and longterm (e.g., reduction in chronic pain and improvement in HRQL) benefits during a patient's convalescence [2].

Postoperative pain control may result in improved cost effectiveness, more appropriate and efficient use of resources, and ultimately improved patient satisfaction [3]. Opioid analgesics, with their well-known side-effects, continue to represent a cornerstone in postoperative pain control, and testing new analgesics as well as combinations of analgesics in order to reduce the need for opioids, is a key area in acute pain research [4]. Due to the relative side-effect potential with increasing doses of opioids, like ventilatory depression, sedation, nausea, vomiting, tolerance and hyperalgesia of the opioid analgesics, many adjuvants have been used to decrease the opioid dose and concomitant side-effects [5]. Adjuvants are compounds which by themselves have low potency but in combination with opioids allow a reduction of narcotic dosing for postoperative pain control. $\alpha_{2}$ adrenergic agonists, clonidine and dexmedetomidine, may be administered preoperatively to provide analgesia and sedation and anxiolysis.They can provide pain relief by an opioid-independent mechanism [6]. Clonidine provides significant benefits for preoperative anxiety and analgesia [7]. The major clinical place of clonidine may thus be as an adjuvant to other analgesic. However, the analgesic effect of oral clonidine has been controversial. Some investigation showed that oral clonidine had not only a good analgesic effect, but also a synergic effect with opioids administered by the neuroaxial route [8]. The $\alpha_{2} \delta$-subunit calcium channel ligands, Gabapentin and Pregabalin, are effective analgesics not only for treatment of neuropathic pain but also acute postoperative pain. When these drugs are combined with opioids or NSAIDs, they act synergistically in attenuating the hyperalgesia associated with peripheral inflammation [9].

Our study was designed to compare two adjuvants, Clonidine, an $\alpha_{2}$ agonist and Gabapentin, an anticonvulsant with a placebo for their relative efficacy in reducing postoperative pain and decreasing opioid requirement in patients undergoing elective gastrectomy of less than 3 hour duration.

\section{Materials and Methods}

This prospective, randomized, double blind, placebo controlled study was conducted after institutional ethical committee approval. Ninety patients, 45-65 years, of both genders, classified as ASA physical status I-II, consenting for participation and undergoing elective gastrectomy under general anaesthesia were selected for the study. Patients with opioid allergy, asthma, renal insufficiency, history of peptic ulcer or bleeding diathesis, mental impairment, chronic pain, cardiovascular, hepatic or renal diseases, BMI over 35, patients who received analgesic or opioids $48 \mathrm{~h}$ before surgery, drug or alcoholic abusers and surgery time over $3 \mathrm{~h}$ were excluded from the study. Preanesthetic visit included review of medical and surgical history, focussed clinical examination and review 


\section{Anaesthesia \& Critical Care Medicine Journal}

of investigations. Patients were educated about study plan. They were demonstrated the VAS pain scoring system and the way of post operative pain control. No premedication was given to the patients. Patients were allocated to three groups as per randomisation. The patients were unaware of their allocated study group

Group 1: received $600 \mathrm{mg}$ Tab Gabapentin at 10: $00 \mathrm{pm}$ the night before and $1 \mathrm{~h}$ before the surgery.

Group 2: received $100 \mu \mathrm{g}$ Tab Clonidine at 10:00 pm the night before and $1 \mathrm{~h}$ before the surgery.

Group 3: received a placebo at 10:00 pm the night before and $1 \mathrm{~h}$ before surgery.

The resident anesthesiologists involved in intraoperative and postoperative patient management were blinded to the study group of the patients.

On arrival in operating room intravenous access was established and patients received normal saline $(0.9 \%)$ solution $7 \mathrm{~mL} \mathrm{~kg}^{-1}$. Standard monitoring was established and heart rates, SP02, MAP were measured before induction of anesthesia. All patients were given Fentanyl $2.5 \mu \mathrm{g} \mathrm{kg}^{-1} 3$ minutes before induction of anesthesia. Anesthesia was induced with Sodium Thiopental $5 \mathrm{mg} \mathrm{kg}$ ${ }^{1}$ and Atracurium $0.5 \mathrm{mg} \mathrm{kg}^{-1}$. Airway was secured using appropriate size PVC endotracheal tube. Anesthesia was maintained with 1 MAC Isoflurane in combination with nitrous oxide $50 \%$ in oxygen. Further boluses of Fentanyl $1 \mu \mathrm{g} / \mathrm{kg}$ and Atracurium $0.1 \mathrm{mg} / \mathrm{kg}$ depending on decision of anesthesiologist were given. Ventilation was mechanically controlled. Inj Granisetron $40 \mu \mathrm{g} / \mathrm{kg}$ was injected 15 minutes prior to reversal. At the end of surgery neuromuscular blockade was antagonized with Neostigmine $70 \mu \mathrm{g} / \mathrm{kg}$ and Glycopyrollate $10 \mu \mathrm{g} / \mathrm{kg}$. After tracheal extubation patients were transferred to Post Anesthesia Care Unit (PACU) Post operative pain assessment was done according to $10 \mathrm{~cm}$ VAS, where $0=$ no pain and $10=$ the worst possible pain. Patients were monitored in recovery room till patient had VAS $\leq 3$. Patients were discharged to postoperative ward with Alderate score of $\geq 9$. All enrolled patients received postoperative intravenous analgesia as boluses of $1 \mathrm{mg}$ Morphine with an interval of 10 minutes between the subsequent doses titrated to VAS $\leq 3$ or appearance of side effects as assessed by the experienced nursing staff of the postoperative ward (HDU). Pain score, heart rate, MAP, $\mathrm{SpO}_{2}$, sedation level and total Morphine dose were assessed and recorded after $1 \mathrm{~h}, 4 \mathrm{~h}, 8 \mathrm{~h}, 12 \mathrm{~h}, 24 \mathrm{~h}$ and $48 \mathrm{~h}$ of the end of surgery. Sedation was assessed according to modified Ramsay sedation scale. Complications such as nausea and vomiting, dizziness, pruritis were also recorded. Nausea and vomiting episodes were treated with Inj metoclopromide $(10 \mathrm{mg})$. Sample size of 30 patients showed power of $80 \%$ and significance level of $5 \%$. The statistical analysis of the data represented as mean \pm standard deviation, was done by using one way ANOVA and t-test for the difference of means for parametric data and chi-square test for the nominal data. These tests were referred for $p$ values for their significance. Any p value less than 0.05 was taken to be statistically significant. The analysis of the data was performed by using statistical package for social sciences (SPSS version 20.00)

\section{Results}

The treatment groups were comparable with respect to age, weight, height, sex distribution, ASA class and duration of surgery (Table 1).

\begin{tabular}{|c|c|c|c|}
\hline Parameters & Group A & Group B & Group C \\
\hline Number(N) & 30 & 30 & 30 \\
\hline Age(years) & $54.00 \pm 2.49$ & $54.63 \pm 2.40$ & $54.63 \pm 2.40$ \\
\hline Weight(kg) & $61.50 \pm 8.87$ & $62.50 \pm 10.99$ & $63.20 \pm 9.50$ \\
\hline Height(cm) & $160.3 \pm 6.49$ & $169.2 \pm 6.07$ & $166.4 \pm 5.44$ \\
\hline Gender(M/F) & $21 / 9$ & $22 / 8$ & $21 / 9$ \\
\hline ASA status I/II & $25 / 5$ & $26 / 4$ & $27 / 3$ \\
\hline $\begin{array}{c}\text { Duration of } \\
\text { surgery }\end{array}$ & $161.00 \pm 7.59$ & $158.50 \pm 6.58$ & $158.17 \pm 5.65$ \\
\hline
\end{tabular}

Table 1: Patient demographic characteristics.

Values in the table are mean $\pm S D$ or absolute numbers (percentage). $S D=$ Standard deviation, $A S A=$ American Society of Anesthesiologists.

The VAS pain scores at measured times were significantly lower in the gabapentin $(4.43 \pm 0.504$, $3.53 \pm 0.507,2.53 \pm 0.506,1.33 \pm 0.479,0.55 \pm 0.507)$ group as compared to clonidine ( $5.03 \pm 0.183,4.93 \pm 0.450$, $3.60 \pm 0.724,1.80 \pm 0.847,0.93 \pm 0.450$ ) and placebo group $(5.70 \pm 0.651, \quad 4.63 \pm 0.490, \quad 4.43 \pm 0.504, \quad 3.10 \pm 0.712$, $1.77 \pm 0.679$ ) (Table 2). The post-operative opioid consumption in Gabapentin group $(15.57 \pm 1.01 \mathrm{mg})$ was significantly less than Clonidine $(19.7 \pm 1.64 \mathrm{mg}, \mathrm{P}<0.05)$ and placebo groups $(25.37 \pm 0.99 \mathrm{mg}) \mathrm{P}<0.001$ (Table 3). Number of patients required $>$ one dose of rescue analgesic were highest in placebo (30) group as compared to group I (3) and group II (9) Table 3. There was no significant difference between the groups regarding the postoperative complications (Table 4). 


\section{Anaesthesia \& Critical Care Medicine Journal}

\begin{tabular}{|c|c|c|c|c|c|c|}
\hline Pain Scale & \multicolumn{2}{|c|}{ Gabapentin } & \multicolumn{2}{c|}{ Clonidine } & \multicolumn{2}{c|}{ Control } \\
\hline & MEAN & SD & MEAN & SD & MEAN & SD \\
\hline $1 \mathrm{H}^{*} \ddagger$ & 4.43 & 0.504 & 5.03 & 0.183 & 5.7 & 0.651 \\
\hline $4 \mathrm{H}^{*}$ & 4.43 & 0.504 & 4.77 & 0.568 & 5.07 & 0.521 \\
\hline $8 \mathrm{H}^{*} \ddagger$ & 3.53 & 0.507 & 4.93 & 0.45 & 4.63 & 0.49 \\
\hline $12 \mathrm{H}^{*} \dagger \neq$ & 2.53 & 0.507 & 3.6 & 0.724 & 4.43 & 0.504 \\
\hline $24 \mathrm{H}^{*} \dagger$ & 1.33 & 0.479 & 1.8 & 0.847 & 3.1 & 0.712 \\
\hline $48 \mathrm{H}^{*}$ & 0.53 & 0.507 & 0.93 & 0.45 & 1.77 & 0.679 \\
\hline
\end{tabular}

Table: 2: Over all VAS over $48 \mathrm{~h}$ postoperatively.

\begin{tabular}{|c|c|c|c|}
\hline Variables & Group A & Group B & Group C \\
\hline Number(N) & 30 & 30 & 30 \\
\hline $\begin{array}{c}\text { Total amount of } \\
\text { Morphine in mg }\end{array}$ & $15.57 \pm 1.01$ & $19.7 \pm 1.64$ & $25.37 \pm 0.99$ \\
\hline $\begin{array}{l}\text { No of pt required }>1 \text { dose } \\
\text { of rescue analgesic (\%) }\end{array}$ & $3(10 \%)$ & $9(30 \%)$ & $30(100 \%)$ \\
\hline
\end{tabular}

Table 3: Rescue analgesic requirement.

\begin{tabular}{|c|c|c|c|}
\hline Side Effects & Group I & Group Ii & Group Iii \\
\hline Dizziness & 6 & 5 & 1 \\
\hline Somnolence & 5 & 4 & 0 \\
\hline Blurred vision & 0 & 0 & 0 \\
\hline Headache & 1 & 1 & 0 \\
\hline Peripheral edema & 0 & 0 & 0 \\
\hline
\end{tabular}

Table 4: Post operative side effects.

\section{Discussion}

Although, there are studies regarding Gabapentin a nd Clonidine effects on decreasing postoperative pain, our placebo-controlled study compares these two drugs in decreasing postoperative pain and opioid consumption in patients undergoing gastrectomy. . The results from our study administering oral gabapentin or clonidine before abdominal gastrectomy comparing to the group receiving placebo show a VAS pain score reduction in the former. Postoperative morphine consumption also was significantly decreased without an increase in concomitant side effects.Uncontrolled postoperative pain may produce a range of detrimental acute and chronic effects. The perioperative period is associated with a variety of pathophysiologic responses that may be initiated or maintained by nociceptive input Continuous release of inflammatory mediators in the periphery sensitizes functional nociceptors and activates dormant ones. Central sensitization and hyperexcitability develop after the surgical incision and result in amplification of postoperative pain [2]. 


\section{Anaesthesia \& Critical Care Medicine Journal}

breast surgery for cancer [21]. In a study conducted in patients undergoing craniotomy for supratentorial tumor resection administration of gabapentin was effective for acute postoperative pain [22]. It also decreased analgesic consumption after surgery. However, it leads to side effects such as delayed tracheal extubation and increased sedation postoperatively. In our study sedation scores were comparable in all the three groups at all times. A few studies did show more sedation in Gabapentin and Clonidine groups as compared to the placebo group. Gilron, et al. [12] in their study in abdominal hysterectomy patients found more sedation in gabapentin group when compared with either refecoxcib or refecoxcib-gabapentin group. However, they used $1800 \mathrm{mg} /$ day over $72 \mathrm{~h}$ starting from $1 \mathrm{~h}$ preoperatively. Other side effects evaluated included nausea, vomiting and pruritis. None of these achieved statistical significance among the three groups which is in concordance with previous studies [23-25]. Clonidine binds to presynaptic $\alpha_{2}$ receptors, decreasing the release of norepinephrine to produce analgesia [26]. Clonidine has pharmacologic characteristics (sedation, hypnosis, anxiolysis, sympatholysis, and analgesia) that make it suitable as adjuvants to multimodal analgesia [27]. Clonidine is a selective partial agonist for the alpha adrenoreceptor. The $\alpha_{2} / \alpha_{1}$ binding ratios for Clonidine is 220:1. Clonidine can be administered orally, transdermally, intravenously and neuraxially for perioperative pain management [6], Marashi, et al. [28] in their study in patients undergoing thyroidectomy showed significantly lower VAS score in clonidine and Gabapentin groups than placebo group. In another study, in patients undergoing laparoscopic cholecystectomy oral Clonidine $150 \mu \mathrm{g}$ as a pre-medicant resulted in improved perioperative hemodynamic stability and a reduction in the intra-operative anesthetic and a prolonged time interval to the first request of analgesia postoperatively compared to the control group [29]. Bradycardia and hypotension are the adverse effects related to $\alpha_{2}$ agonists if the dose exceeds $150 \mu \mathrm{g}$ as part of a peripheral nerve block $[26,30]$. Our study proved clonidine to have insignificant effect on hemodynamics with improved pain score and opioid sparing effect. The patients in our study never experienced hypotension and bradycardia. But all of our patients were ASA physical status I-II, so additional studies are necessary to deem the study drugs to be safer in patients with significant comorbidities. Another limitation of our study was the use of boluses of morphine. The use of PCA pump could have been more effective, however it would increase the costs. Gabapentin and clonidine also provide sedation and anxiolysis in preoperative period. The data for this was not analyzed in this study and hence further studies are necessary to prove their anxiolytic actions and intraoperative effects on opioids requirements.

\section{Conclusion}

Our study concluded that administration of $1200 \mathrm{mg}$ of gabapentin or $200 \mu \mathrm{g}$ clonidine preoperatively significantly reduces VAS score and opioid consumption when compared to placebo in patients undergoing gastrectomy. Also Gabapentin was more effective than clonidine in reducing postoperative pain and morphine use for analgesia.

\section{References}

1. Barr J, Zomorodi K, Bertaccini E, Shafer S, Geller E (2013) A Double-blind, Randomized Comparison of IV Lorazepam versus Midazolam for Sedation of ICU Patients via a Pharmacologic Model. Anesthesiology 95(2): 286-298.

2. Miller R. Miller's (2009) anesthesia. (7th edn), PA: Churchill Livingstone/Elsevier, Philadelphia, pp: 2758-2759

3. Mesoli, Govegoankar (2003) Post-Op Pain Relief for Ambulatory Surgery. Indian Medical Gazette 138-150.

4. Pyati S, Gan TJ (2007) Perioperative pain management. CNS Drugs 21(3): 185-211.

5. Wewers M, Lowe N (1990) a critical review of visual analogue scales in the measurement of clinical phenomena. Research in nursing \& health 13 (4): 227-236.

6. Gabriel J, Gordin V (2001) Alpha agonists in regional anesthesia and analgesia. Current Opinion in Anesthesiology 14 (6): 751-755.

7. Hidalgo MP, Auzani JA, Rumpel LC, Moreira NL Jr, Cursino AW, et al. (2005) The clinical effect of small oral clonidine doses on perioperative outcomes in patients undergoing abdominal hysterectomy. Anesthesia Analgesia 100(3): 795-780.

8. Goyagi T, Tanaka M, Nishikawa T (1999) Oral clonidine premedication enhances postoperative analgesia by epidural morphine. Anesthesia Analgesia 89(6): 1487-1491. 


\section{Anaesthesia \& Critical Care Medicine Journal}

9. Barash P, Cullen B, Stoelting R (2009) Clinical anesthesia. (6th edn), Lippincott Williams \& Wilkins, Philadelphia, pp: 1487(6).

10. Rose M, Kam P (2002) Gabapentin: pharmacology and its use in pain management. Anaesthesia 57 (5): 451462.

11. Rosenberg JM, Harrell C, Ristic H, Werner RA, de Rosayro AM (1997) The effect of gabapentin on neuropathic pain. Clinical Journal of Pain 13(3): 251255.

12. Gilron I, Orr E, Tu D, O'Neill JP, Zamora JE, et al. (2005) A placebo-controlled randomized clinical trial of perioperative administration of gabapentin, rofecoxib and their combination for spontaneous and movement-evoked pain after abdominal hysterectomy. Pain 113(1-2): 191-200.

13. Durmus M, Kadir But A, Saricicek V, Ilksen Toprak H, Ozcan Ersoy M (2007) The post-operative analgesic effects of a combination of gabapentin and paracetamol in patients undergoing abdominal hysterectomy: a randomized clinical trial. Acta anaesthesiologica scandinavica 51 (3): 299-304.

14. Saraswat V, Arora V, Others (2008) Preemptive gabapentin vs pregabalin for acute postoperative pain after surgery under spinal Anaesthesia. Indian Journal of Anaesthesia 52 (6): 829.

15. Pandey CK, Sahay S, Gupta D, Ambesh SP, Singh RB, et al. (2004) Preemptive gabapentin decreases postoperative pain after lumbar discoidectomy. Canadian journal of anaesthesia 51(10): 986-989.

16. Ménigaux C, Adam F, Guignard B, Sessler DI, Chauvin $M$ (2005) Preoperative gabapentin decreases anxiety and improves early functional recovery from knee surgery. Anesthesia Analgesia 100(5): 1394-1399.

17. Dierking G, Duedahl TH, Rasmussen ML, Fomsgaard JS, Møiniche S, et al. (2004) Effects of gabapentin on postoperative morphine consumption and pain after abdominal hysterectomy: a randomized, double-blind trial. Acta anaesthesiologica scandinavica 48 (3): 322327.

18. Turan A, Karamanlioğlu B, Memiş D, Hamamcioglu MK, Tükenmez B, et al. (2004) Analgesic effects of gabapentin after spinal surgery. Anesthesiology 100(4): 935-938.
19. Rorarius M, Menn, Er S, Suominen P, Rintala S, Puura A, et al. (2004) Gabapentin for the prevention of postoperative pain after vaginal hysterectomy. Pain 110 (1): 175-181.

20. Soltanzadeh M, Ebad A, Pipelzadeh M, Tabatabaei S, Firouzabadi M, et al. (2011) Gabapentin May Relieve Post-Coronary Artery Bypass Graft Pain: A Double Blind Randomized Clinical Trial. Iranian Cardiovascular Research Journal 5 (3): 79-82.

21. Fassoulaki A, Triga A, Melemeni A, Sarantopoulos C (2005) Multimodal analgesia with gabapentin and local anesthetics prevents acute and chronic pain after breast surgery for cancer. Anesthesia Analgesia 101(5): 1427-1432.

22. Türe H, Sayin M, Karlikaya G, Bingol CA, Aykac B, et al. (2009) the analgesic effect of gabapentin as a prophylactic anticonvulsant drug on postcraniotomy pain: a prospective randomized study. Anesthesia Analgesia 109(5): 1625-1631.

23. Benhamou D, Narchi P, Hamza J, Marx M, Peyrol M, et al. (1994) Addition of oral clonidine to postoperative patient-controlled analgesia with iv morphine. British journal of anaesthesia 72 (5): 537-540.

24. Yoshikawa $\mathrm{T}$, Wajima $\mathrm{Z}$, Ogura $\mathrm{A}$, Inoue $\mathrm{T}$, Ogawa $\mathrm{R}$ (2001) Orally administered clonidine significantly reduces pain during injection of propofol. British journal of anaesthesia 86 (6): 874-876.

25. Mohammadi SS, Seyedi M (2008) Effects of gabapentin on early postoperative pain, nausea and vomiting in laparoscopic surgery for assisted reproductive technologies. Pakistani Journal of Biological Sciences 11(14): 1878-1880.

26. Barash P, Cullen B, Stoelting R (2009) Clinical anesthesia. (6th edn), Lippincott Williams \& Wilkins, Philadelphia, pp: 1486.

27. Kehlet H, Dahl JB (2003) Anaesthesia, surgery, and challenges in postoperative recovery. Lancet 362(9399): 1921-1928.

28. Marashi S, Morabi A, Ghafari M, Azimaraghi O, Movafegh A (2012) The Effect of Pre-operative Oral Clonidine or Gabapentin on Post-operative Pain intensity, Morphine Consumption and Post-operative Nausea and Vomiting in Patients Who Undergone Thyroidectomy: A Double-blind Placebo-control 


\section{Anaesthesia \& Critical Care Medicine Journal}

Study. Journal of Anesthesia \& Clinical Research 3 (4): 206.

29. Singh S, Arora K (2011) Effect of oral clonidine premedication on perioperative haemodynamic response and postoperative analgesic requirement for patients undergoing laparoscopic cholecystectomy. Indian Journal of Anaesthesia 55(1): 26-30.
30. Sung C, Lin S, Chan K, Chang W, Chow L, et al. (2000) Effect of oral clonidine premedication on perioperative hemodynamic response and postoperative analgesic requirement for patients undergoing laparoscopic cholecystectomy.. Acta anaesthesiologica Sinica 38 (1): 23-29. 